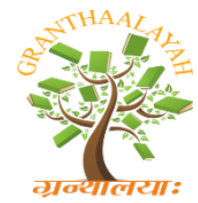

\author{
INTERNATIONAL JOURNAL OF RESEARCH - \\ GRANTHAALAYAH \\ A knowledge Repository
}

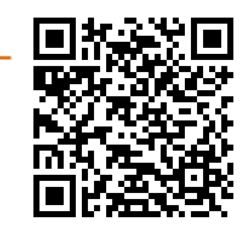

Science

\title{
MINIMIZATION OF REAL POWER LOSS BY ENHANCED GRAVITATIONAL SEARCH ALGORITHM
}

\author{
Dr.K.Lenin *1 \\ ${ }^{* 1}$ Professor, Department of EEE, Prasad V.Potluri Siddhartha Institute of Technology, Kanuru, \\ Vijayawada, Andhra Pradesh -520007, India
}

\begin{abstract}
In this paper, Enhanced Gravitational Search (EGS) algorithm is proposed to solve the reactive power problem. Gravitational search algorithm (GSA) results are improved by using artificial bee colony algorithm (ABC). In GSA, solutions are fascinated towards each other by applying gravitational forces, which depending on the masses assigned to the solutions, to each other. The heaviest mass will move slower than other masses and pull others. Due to nature of gravitation, GSA may pass global minimum if some solutions stuck to local minimum. ABC updates the positions of the best solutions that have obtained from GSA, preventing the GSA from sticking to the local minimum by its strong penetrating capability. The proposed algorithm improves the performance of GSA in greater level. In order to evaluate the performance of the proposed EGS algorithm, it has been tested on IEEE 57,118 bus systems and compared to other standard algorithms.
\end{abstract}

Keywords: Gravitational Search Algorithm; Artificial Bee Colony Algorithm; Reactive Power; Transmission Loss.

Cite This Article: Dr.K.Lenin. (2017). "MINIMIZATION OF REAL POWER LOSS BY ENHANCED GRAVITATIONAL SEARCH ALGORITHM." International Journal of Research - Granthaalayah, 5(7), 623-630. https://doi.org/10.29121/granthaalayah.v5.i7.2017.2171.

\section{Introduction}

Various mathematical techniques have been adopted to solve this optimal reactive power dispatch problem. These include the gradient method [1, 2], Newton method [3] and linear programming [4-7].The gradient and Newton methods suffer from the difficulty in handling inequality constraints. To apply linear programming, the input- output function is to be expressed as a set of linear functions which may lead to loss of accuracy. Recently Global Optimization techniques such as genetic algorithms have been proposed to solve the reactive power flow problem [8-14]. In this paper, Enhanced Gravitational Search (EGS) algorithm is proposed to solve the reactive power problem. Gravitational search algorithm (GSA) performance is improved by using artificial bee colony algorithm (ABC). GSA [15] can be considered as a collection of agents (candidate solutions) whose have masses proportional to their value of 
fitness function. During generations, all masses attract each other by the gravity forces between them. Artificial Bee Colony (ABC) [16] Algorithm is an optimization algorithm based on the intellectual foraging behavior of honey bee swarm Due to nature of gravitation, GSA may pass global minimum if some solutions stuck to local minimum. ABC updates the positions of the best solutions that have obtained from GSA, preventing the GSA from sticking to the local minimum by its strong penetrating capability. Both the exploration \& exploitation ability of the proposed EGS algorithm has been enhanced. The performance of Enhanced Gravitational Search (EGS) algorithm has been evaluated in standard IEEE 57,118 bus test systems and the results analysis shows that our proposed approach outperforms all approaches investigated in this paper.

\section{Objective Function}

Active power loss

Main aim of the reactive power dispatch problem is to reduce the active power loss in the transmission network, which can be described as:

$F=P L=\sum_{k \in N b r} g_{k}\left(V_{i}^{2}+V_{j}^{2}-2 V_{i} V_{j} \cos \theta_{i j}\right)$

Where $g_{k}$ : is the conductance of branch between nodes $i$ and $j$, Nbr: is the total number of transmission lines in power systems.

\section{Voltage profile improvement}

For minimization of the voltage deviation in PQ buses, the objective function turns into:

$F=P L+\omega_{v} \times V D$

Where $\omega_{\mathrm{v}}$ : is a weighting factor of voltage deviation.

$\mathrm{VD}$ is the voltage deviation given by:

$V D=\sum_{i=1}^{N p q}\left|V_{i}-1\right|$

\section{Equality Constraint}

The equality constraint of the Reactive power problem is represented by the power balance equation, and can be written as, where the total power generation must cover the total power demand and total power loss:

$P_{G}=P_{D}+P_{L}$

Where, $P_{G}$ - Total Power Generation, $P_{D}$-Total Power Demand, $P_{L}-$ Total Power Loss.

\section{Inequality Constraints}

Inequality constraints define the limitations in power system components and power system security. Upper and lower bounds on the active power of slack bus, and reactive power of generators are written as follows:

$P_{\text {gslack }}^{\min } \leq P_{\text {gslack }} \leq P_{\text {gslack }}^{\text {max }}$

$Q_{g i}^{\min } \leq Q_{g i} \leq Q_{g i}^{\max }, i \in N_{g}$

Upper and lower bounds on the bus voltage magnitudes are described as follows:

$V_{i}^{\min } \leq V_{i} \leq V_{i}^{\max }, i \in N$

Upper and lower bounds on the transformers tap ratios are given as follows:

$T_{i}^{\text {min }} \leq T_{i} \leq T_{i}^{\text {max }}, i \in N_{T}$

Upper and lower bounds on the compensators reactive powers are written as follows: 
$Q_{c}^{\min } \leq Q_{c} \leq Q_{C}^{\max }, i \in N_{C}$

Where $\mathrm{N}$ is the total number of buses, $\mathrm{N}_{\mathrm{T}}$ is the total number of Transformers; $\mathrm{N}_{\mathrm{c}}$ is the total number of shunt reactive compensators.

\section{Gravitational Search Algorithm}

Gravitational Search Algorithm (GSA) is a novel heuristic optimization method which inspired from the Newton's theory \& that states: Every particle in the universe attracts every other particle with a force that is directly proportional to the product of their masses and inversely proportional to the square of the distance between them .GSA can be considered as a collection of agents (candidate solutions) whose have masses proportional to their value of fitness function. During generations, all masses attract each other by the gravity forces between them .A heavier mass has the bigger attraction force. Therefore, the heavier masses which are probably close to the global Optimum attract the other masses proportional to their Distances. The GSA was mathematically modelled as follow. Suppose a system with $\mathrm{N}$ agents. The algorithm starts with randomly placing all agents in search space. During all epochs, the gravitational forces from agent $j$ on agent $i$ at a Specific time $t$ is defined as follow;

$F_{i j}^{d}(t)=G(t) \frac{M_{p i}(t) \times M_{a j}(t)}{R_{i j}(t)+\epsilon}\left(x_{j}^{d}(t)-x_{i}^{d}(t)\right)$

The $\mathrm{G}(\mathrm{t})$ is calculated as :

$G(t)=G_{0} \times \exp \left(-a \times \frac{\text { iter }}{\text { maxiter }}\right)$

In a problem space with the dimension $d$, the total force that acts on agent $i$ is calculated as the following equation:

$F_{i}^{d}(t)=\sum_{i=1, j \neq i}^{N} \operatorname{rand}_{j} F_{i j}^{d}(t)$

According to the law of motion, the acceleration of an agent is proportional to the result force and inverse of its mass, so the acceleration of all agents should be calculated as follow:

$a c_{i}^{d}(t)=\frac{F_{i}^{d}(t)}{M_{i i}(t)}$

The velocity and position of agents are calculated as follow:

$$
\begin{gathered}
\operatorname{vel}_{i}^{d}(t+1)=\operatorname{rand}_{i} \times \operatorname{vel}_{i}^{d}(t)+a c_{i}^{d}(t) \\
x_{i}^{d}(t+1)=x_{i}^{d}(t)+\operatorname{vel}_{i}^{d}(t+1)
\end{gathered}
$$

In GSA, at first all masses are initialized with random Values. Each mass is a candidate solution. After Initialization, velocities for all masses are defined using (14).Meanwhile the gravitational constant, total forces, and accelerations are calculated as (11), (12), and (13) respectively. The positions of masses are calculated using (15). Finally GSA will be stopped by meeting an end criterion.

\section{Artificial Bee Colony Algorithm}

Artificial Bee Colony (ABC) algorithm is an optimization algorithm based on the intellectual foraging behavior of honey bee swarm. The colony of artificial bees consists of three groups of bees: employed bees, onlookers and scouts. An employed bee searches the target where the food 
is available. They accumulate the food and returns back to its source where they carry out waggle dance depending on the amount of food available at the target. The onlooker bee observe the dance and follows employed bee depends on the probability of the available food means more onlooker bee will follow the employed bee associated with the target having more amount of food. The employed bee whose food source becomes abandoned then it changes into a scout bee and it will search for the new food source. For solving optimization problems the population is alienated into two parts consisting of employed bees and onlooker bees. An employed bee searches the solution in the explore space and the value of objective function associated with the solution is the amount of food linked with that solution. Employed bee updates its position using Equation (16) and it updates new position if it is better than the preceding position.

$\mathrm{v}_{\mathrm{ij}}=\mathrm{x}_{\mathrm{ij}}+\mathrm{R}_{\mathrm{ij}}\left(\mathrm{x}_{\mathrm{ij}}-\mathrm{x}_{\mathrm{kj}}\right)$

Where vij is the new position of employee bee, $\mathrm{xij}$ is the current position of employed bee, $\mathrm{k}$ is a random number between $(1, \mathrm{~N}$ (population size) $/ 2) \neq \mathrm{i}$ and $\mathrm{j}=1,2, \ldots$, Number of design variables. Rij is a random number between $(-1,1)$.

An onlooker bees prefer a food source depending on the probability value related with that food source, pi , calculated using Equation (17).

$\mathrm{P}_{\mathrm{i}}=\frac{\mathrm{F}_{\mathrm{i}}}{\sum_{\mathrm{n}=1}^{\mathrm{N} / 2} \mathrm{~F}_{\mathrm{n}}}$

Where $\mathrm{Fi}$ is the fitness value of the solution $\mathrm{i}$ and N/2 is the number of food sources which is equal to the number of employed bees.

The Employed bee whose location of the food source cannot be enhanced for some predetermined number of cycles than that food source is called abandoned food source. That employed bee becomes scout and searches for the new solution randomly using Equation (18).

$x_{i}^{\mathrm{j}}=\mathrm{x}_{\min }^{\mathrm{j}}+\operatorname{rand}(0,1)\left(\mathrm{x}_{\max }^{\mathrm{j}}-\mathrm{x}_{\min }^{\mathrm{j}}\right)$

\section{Enhanced Gravitational Search (EGS) Algorithm}

The proposed Enhanced Gravitational Search (EGS) algorithm is mainly based on the improvement of the results of the gravitational search algorithm (GSA) using the artificial bee colony algorithm (ABC). The half of the best population found by gravitational search algorithm sent to the artificial bee colony algorithm to start employed bees.

Algorithm steps are given below.

1) Initialize parameters.

2) Create starting population.

3) Calculate fitness for current solution set.

4) Calculate Mass, Forces and Acceleration for each solution.

5) Update velocities and positions of candidate solutions.

6) Calculate fitness for updated solution set.

7) Select best number of populations/2 from solution set.

8) Send employed bees to food sources (solutions).

9) Send onlooker bees to food sources provided by employed bees.

10) If termination criteria provided return best solution else return step 4 and run until termination criteria provided. 


\section{Simulation Results}

At first Enhanced Gravitational Search (EGS) algorithm has been tested in standard IEEE-57 bus power system. The reactive power compensation buses are 18, 25 and 53. Bus 2, 3, 6, 8, 9 and 12 are PV buses and bus 1 is selected as slack-bus. The system variable limits are given in Table 1. The preliminary conditions for the IEEE-57 bus power system are given as follows:

$\mathrm{P}_{\text {load }}=12.112$ p.u. Q $_{\text {load }}=3.032$ p.u.

The total initial generations and power losses are obtained as follows:

$\sum P_{G}=12.421$ p.u. $\sum Q_{G}=3.3132$ p.u.

$\mathrm{P}_{\text {loss }}=0.25882$ p.u. $\mathrm{Q}_{\text {loss }}=-1.2062$ p.u.

Table 2 shows the various system control variables i.e. generator bus voltages, shunt capacitances and transformer tap settings obtained after optimization which are within the acceptable limits. In Table 3, shows the comparison of optimum results obtained from proposed methods with other optimization techniques. These results indicate the robustness of proposed approaches for providing better optimal solution in case of IEEE-57 bus system.

Table 1: Variable Limits

\begin{tabular}{|c|c|c|c|c|c|c|c|c|}
\hline \multicolumn{9}{|c|}{ Reactive Power Generation Limits } \\
\hline Bus no & 1 & \multicolumn{2}{|c|}{2} & 3 & 6 & 8 & 9 & 12 \\
\hline Qgmin & -1.4 & \multicolumn{2}{|c|}{-.015} & -.02 & -0.04 & -1 & -0.03 & -0.4 \\
\hline Qgmax & 1 & \multicolumn{2}{|c|}{0.3} & 0.4 & 0.21 & 1 & 0.04 & 1.50 \\
\hline \multicolumn{9}{|c|}{ Voltage And Tap Setting Limits } \\
\hline vgmin & \multicolumn{2}{|c|}{ Vgmax } & \multicolumn{2}{|c|}{ vpqmin } & \multicolumn{2}{|c|}{ Vpqmax } & tkmin & tkmax \\
\hline 0.9 & \multicolumn{2}{|c|}{1.0} & \multicolumn{2}{|c|}{0.91} & \multicolumn{2}{|c|}{1.05} & 0.9 & 1.0 \\
\hline \multicolumn{7}{|c|}{ Shunt Capacitor Limits } & & \\
\hline Bus no & \multicolumn{2}{|c|}{18} & \multicolumn{2}{|c|}{25} & \multicolumn{2}{|l|}{53} & & \\
\hline Qcmin & \multicolumn{2}{|l|}{0} & \multicolumn{2}{|c|}{0} & \multicolumn{2}{|l|}{0} & & \\
\hline Qcmax & \multicolumn{2}{|l|}{10} & \multicolumn{2}{|c|}{5.2} & \multicolumn{2}{|l|}{6.1} & & \\
\hline
\end{tabular}

Table 2: Control variables obtained after optimization

\begin{tabular}{|l|l|}
\hline Control Variables & EGS \\
\hline V1 & 1.1 \\
\hline V2 & 1.030 \\
\hline V3 & 1.033 \\
\hline V6 & 1.022 \\
\hline V8 & 1.024 \\
\hline V9 & 1.008 \\
\hline V12 & 1.016 \\
\hline Qc18 & 0.0661 \\
\hline Qc25 & 0.200 \\
\hline Qc53 & 0.0472 \\
\hline T4-18 & 1.009 \\
\hline T21-20 & 1.042 \\
\hline T24-25 & 0.866 \\
\hline
\end{tabular}




\begin{tabular}{|l|l|}
\hline T24-26 & 0.878 \\
\hline T7-29 & 1.050 \\
\hline T34-32 & 0.871 \\
\hline T11-41 & 1.012 \\
\hline T15-45 & 1.034 \\
\hline T14-46 & 0.910 \\
\hline T10-51 & 1.020 \\
\hline T13-49 & 1.060 \\
\hline T11-43 & 0.910 \\
\hline T40-56 & 0.900 \\
\hline T39-57 & 0.950 \\
\hline T9-55 & 0.950 \\
\hline
\end{tabular}

Table 3: Comparison results

\begin{tabular}{|l|l|l|l|l|}
\hline S.No. & Optimization Algorithm & Finest Solution & Poorest Solution & Normal Solution \\
\hline 1 & NLP [17] & 0.25902 & 0.30854 & 0.27858 \\
\hline 2 & CGA [17] & 0.25244 & 0.27507 & 0.26293 \\
\hline 3 & AGA [17] & 0.24564 & 0.26671 & 0.25127 \\
\hline 4 & PSO-w [17] & 0.24270 & 0.26152 & 0.24725 \\
\hline 5 & PSO-cf [17] & 0.24280 & 0.26032 & 0.24698 \\
\hline 6 & CLPSO [17] & 0.24515 & 0.24780 & 0.24673 \\
\hline 7 & SPSO-07 [17] & 0.24430 & 0.25457 & 0.24752 \\
\hline 8 & L-DE [17] & 0.27812 & 0.41909 & 0.33177 \\
\hline 9 & L-SACP-DE [17] & 0.27915 & 0.36978 & 0.31032 \\
\hline 10 & L-SaDE [17] & 0.24267 & 0.24391 & 0.24311 \\
\hline 11 & SOA [17] & 0.24265 & 0.24280 & 0.24270 \\
\hline 12 & LM [18] & 0.2484 & 0.2922 & 0.2641 \\
\hline 13 & MBEP1 [18] & 0.2474 & 0.2848 & 0.2643 \\
\hline 14 & MBEP2 [18] & 0.2482 & 0.283 & 0.2592 \\
\hline 15 & BES100 [18] & 0.2438 & 0.263 & 0.2541 \\
\hline 16 & BES200 [18] & 0.3417 & 0.2486 & 0.2443 \\
\hline 17 & Proposed EGS & 0.22062 & 0.23012 & 0.22302 \\
\hline
\end{tabular}

Then Enhanced Gravitational Search (EGS) algorithm has been tested in standard IEEE 118-bus test system [19].The system has 54 generator buses, 64 load buses, 186 branches and 9 of them are with the tap setting transformers. The limits of voltage on generator buses are $0.95-1.1$ perunit., and on load buses are $0.95-1.05$ per-unit. The limit of transformer rate is $0.9-1.1$, with the changes step of 0.025 . The limitations of reactive power source are listed in Table 4, with the change in step of 0.01 .

Table 4: Limitation of reactive power sources

\begin{tabular}{|l|l|l|l|l|l|l|l|}
\hline BUS & 5 & 34 & 37 & 44 & 45 & 46 & 48 \\
\hline QCMAX & 0 & 14 & 0 & 10 & 10 & 10 & 15 \\
\hline QCMIN & -40 & 0 & -25 & 0 & 0 & 0 & 0 \\
\hline BUS & 74 & 79 & 82 & 83 & 105 & 107 & 110 \\
\hline
\end{tabular}




\begin{tabular}{|l|l|l|l|l|l|l|l|}
\hline QCMAX & 12 & 20 & 20 & 10 & 20 & 6 & 6 \\
\hline QCMIN & 0 & 0 & 0 & 0 & 0 & 0 & 0 \\
\hline
\end{tabular}

The statistical comparison results of 50 trial runs have been list in Table 5 and the results clearly show the better performance of proposed Enhanced Gravitational Search (EGS) algorithm in reducing the real power loss.

Table 5: Comparison results

\begin{tabular}{|l|c|l|l|l|}
\hline $\begin{array}{c}\text { Active power loss } \\
\text { (MW) }\end{array}$ & $\begin{array}{c}\text { BBO } \\
{[\mathbf{2 0}]}\end{array}$ & $\begin{array}{c}\text { ILSBBO/strategy1 } \\
{[\mathbf{2 0}]}\end{array}$ & $\begin{array}{c}\text { ILSBBO/strategy1 } \\
{[\mathbf{2 0}]}\end{array}$ & $\begin{array}{c}\text { Proposed } \\
\text { EGS }\end{array}$ \\
\hline Min & 128.77 & 126.98 & 124.78 & 117.04 \\
\hline Max & 132.64 & 137.34 & 132.39 & 120.08 \\
\hline Average & 130.21 & 130.37 & 129.22 & 118.32 \\
\hline
\end{tabular}

\section{Conclusion}

In this paper Enhanced Gravitational Search (EGS) algorithm has been used to solve reactive power dispatch problem. Both the exploration \& exploitation ability of the proposed EGS algorithm has been enhanced. The effectiveness of the proposed Enhanced Gravitational Search (EGS) algorithm has been demonstrated by testing it in IEEE 57,118 bus system and simuation results reveals about the reduction of real power loss when compared with other standard algorithms and also volatge profiles are within the limits .

\section{References}

[1] O.Alsac, and B. Scott, "Optimal load flow with steady state security", IEEE Transaction. PAS 1973, pp. 745-751.

[2] Lee K Y ,Paru Y M , Oritz J L -A united approach to optimal real and reactive power dispatch , IEEE Transactions on power Apparatus and systems 1985: PAS-104 : 1147-1153

[3] A.Monticelli , M .V.F Pereira ,and S. Granville, "Security constrained optimal power flow with post contingency corrective rescheduling", IEEE Transactions on Power Systems :PWRS-2, No. 1, pp.175-182.,1987.

[4] Deeb N, Shahidehpur S.M, Linear reactive power optimization in a large power network using the decomposition approach. IEEE Transactions on power system 1990: 5(2) : 428-435

[5] E. Hobson ,'Network consrained reactive power control using linear programming, ' IEEE Transactions on power systems PAS -99 (4) ,pp 868-877, 1980

[6] K.Y Lee,Y.M Park, and J.L Oritz, "Fuel -cost optimization for both real and reactive power dispatches", IEE Proc; 131C,(3), pp.85-93.

[7] M.K. Mangoli, and K.Y. Lee, "Optimal real and reactive power control using linear programming”, Electr.Power Syst.Res, Vol.26, pp.1-10,1993.

[8] S.R.Paranjothi, and K.Anburaja, "Optimal power flow using refined genetic algorithm", Electr. Power Compon. Syst, Vol. 30, 1055-1063, 2002.

[9] D. Devaraj, and B. Yeganarayana, "Genetic algorithm based optimal power flow for security enhancement", IEE proc-Generation. Transmission and. Distribution; 152, 6 November 2005.

[10] C.A. Canizares, A.C.Z.de Souza and V.H. Quintana, "Comparison of performance indices for detection of proximity to voltage collapse," vol. 11. no.3, pp.1441-1450, Aug 1996.

[11] $\mathrm{Wu} \mathrm{Q} \mathrm{H}$, Ma J T. Power system optimal reactive power dispatch using evolutionary programming. IEEE Transactions on power systems 1995; 10(3): 1243-1248. 
[12] S.Durairaj, D.Devaraj, P.S.Kannan,' Genetic algorithm applications to optimal reactive power dispatch with voltage stability enhancement', IE(I) Journal-EL Vol 87,September 2006.

[13] D.Devaraj ,' Improved genetic algorithm for multi - objective reactive power dispatch problem' European Transactions on electrical power 2007 ; 17: 569-581.

[14] P. Aruna Jeyanthy and Dr. D. Devaraj "Optimal Reactive Power Dispatch for Voltage Stability Enhancement Using Real Coded Genetic Algorithm" International Journal of Computer and Electrical Engineering, Vol. 2, No. 4, August, 2010 1793-8163.

[15] E. Rashedi, S. Nezamabadi, and S. Saryazdi, "GSA: A GravitationalSearch Algorithm,"Information Sciences, vol. 179, no. 13, pp. 2232-2248, 2009.

[16] Dervis Karaboga,Bahriye, "A comparative study of Artificial Bee Colony algorithm”, Applied Mathmatics and Compution 214 108-132, 2009.

[17] Chaohua Dai, Weirong Chen, Yunfang Zhu, and Xuexia Zhang, "Seeker optimization algorithm for optimal reactive power dispatch," IEEE Trans. Power Systems, Vol. 24, No. 3, August 2009, pp. 1218-1231.

[18] J. R. Gomes and 0. R. Saavedra, "Optimal reactive power dispatch using evolutionary computation: Extended algorithms," IEE Proc.-Gener. Transm. Distrib.. Vol. 146, No. 6. Nov. 1999.

[19] IEEE, "The IEEE 30-bus test system and the IEEE 118-test system", (1993), http://www.ee.washington.edu/trsearch/pstca/.

[20] Jiangtao Cao, Fuli Wang and Ping Li, "An Improved Biogeography-based Optimization Algorithm for Optimal Reactive Power Flow" International Journal of Control and Automation Vol.7, No.3 (2014), pp.161-176.

*Corresponding author.

E-mail address: gklenin@gmail.com 